\title{
Bioluminescent assay for evaluating antimicrobial activity in insect haemolymph
}

\author{
Libor VOJTEK ${ }^{1}$, Pavel DOBEŠ ${ }^{1}$, Ender BÜYÜKGÜZEL ${ }^{2}$, JanNe ATOSUO ${ }^{3}$ and PaVel HYRŠL ${ }^{1}$
}

\begin{abstract}
${ }^{1}$ Department of Animal Physiology and Immunology, Institute of Experimental Biology, Faculty of Science, Masaryk University, Kotlářská 2,61137 Brno, Czech Republic; e-mails: libor.vojtek@mail.muni.cz; pavel.dobes@mail.muni.cz; hyrsl@sci.muni.cz

${ }^{2}$ Department of Molecular Biology and Genetics, Faculty of Sciences and Arts, Bülent Ecevit University, 67100 Zonguldak, Turkey; e-mail: endericen@hotmail.com
\end{abstract}

${ }^{3}$ Department of Biochemistry, Faculty of Mathematics and Natural Sciences, University of Turku, FI-20014 Turku, Finland; e-mail: janato@utu.fi

Key words. Lepidoptera, Bombyx mori, Galleria mellonella, antibacterial activity, antimicrobial peptides, bioluminescent bacteria, Escherichia coli, Photorhabdus luminescens

\begin{abstract}
We describe an antibacterial assay based on bioluminescence of two Gram negative bacteria, Photorhabdus luminescens and transformed Escherichia coli, which can be used as a real-time measurement of antibacterial activity in insect haemolymph. This method is based on the production of the bioluminescence signal depending on the viability of bacterial cells. We observed a significant rapid dose-dependent decrease in bioluminescence using both bacterial species, and Bombyx mori or Galleria mellonella haemolymph, which was confirmed by the decrease in bacterial viability determined by plating. The humoral origin of the antibacterial activity observed in whole haemolymph was confirmed for haemolymph plasma without haemocytes. Antibacterial activity directed against Gram negative bacteria was recorded in unaffected insect larvae as well as after septic injury; increased antibacterial activity of haemolymph was detected in the latter case confirming the inducibility of antimicrobial agents. We think it is likely that this method could be widely used for determining antibacterial activity in insects and other invertebrates.
\end{abstract}

\section{INTRODUCTION}

Bioluminescence is the production and emission of light by living organisms; it is a naturally occurring form of chemiluminescence in which energy is released in the form of light by an enzymatic reaction. In bacteria the expression of genes related to bioluminescence is controlled by lux operon encoding the enzyme luciferase. Although luciferases differ among bacteria they all emit light with a maximum at $490 \mathrm{~nm}$ and the emission requires both a reduced flavin mononucleotide $\left(\mathrm{FMNH}_{2}\right)$ and long-chain aliphatic aldehyde (Poinar et al., 1980).

The genus Photorhabdus (previously known as Xenorhabdus) was described by Boemare et al. (Boemare et al., 1993) and includes terrestrial Gram negative bacteria of the family Enterobacteriaceae, which are mainly found in association with entomopathogenic nematodes Heterorhabditis spp. (Nematoda: Heterorhabditidae). Upon entering an insect host nematodes release bacterial cells from their intestinal tract, which quickly establish a lethal septicaemia in the host (ffrench-Constant et al., 2003). When an insect is infected with Photorhabdus bacteria the carcass becomes visibly bioluminescent (Poinar et al., 1980). In addition to the species of Photorhabdus found in nematodes, $P$. asymbiotica was obtained from human clinical specimens.

Similarly to naturally bioluminescent bacterium, $P$. luminescens, transformed Escherichia coli K12 is capable of light production. This transformed $E$. coli contains a plasmid with the complete luxABCDEamp operon originating from Photorhabdus, which results in the expression of bacterial luciferase and its substrate long-chain aldehyde (Atosuo et al., 2013). This Gram negative bacterium is very sensitive to the vertebrate complement system but not to lytic enzymes such as lysozyme.

Traditionally few methods are used for measuring bacterial viability. The most frequently used method is a colony counting assay carried out using agar plates and estimation of cell number in liquid solutions measured in terms of optical density (OD). To measure kinetic of killing by plating is time-consuming and due to the long incubation time far from real-time. On the other hand OD measurements bring real-time based results, but cannot distinguish between live and dead bacterial cells. Assays based on bacterial bioluminescence offer fast and accurate real-time kinetic viability observation if proven that bioluminescence equals viability (Atosuo et al., 2013). Methods using bioluminescent $E$. coli are routinely used for determining bacteriolytic complement activity (Virta et al., 1997; Nikoskelainen et al., 2002; Kilpi et al., 2009).

Insect immunity in general involves both humoral and cellular activities, which closely interact. Cellular activity of insect immune systems rely on different classes of haemocytes, which phagocytose and form capsules around larger intruders and defend organism against large numbers of bacteria by enclosing them in nodules. Humoral factors are secreted by the fat body and haemocytes into the haemolymph. They include especially highly potent antimicrobial peptides (AMPs) and the enzyme phenoloxidase, whose activity is accompanied by the production of quinones that are both cytotoxic and involved in cross linking of proteins. Activation of phenoloxidase, which leads 
to visible melanisation, also accompanies several cellular reactions (clot and nodule formation as well as encapsulation).

Since the discovery of insect cecropins by Hans Boman in the early 80's a large number of antimicrobial peptides that defend them against microbial pathogens have been described. These peptides are synthesized either by haemocytes or the fat body. It was proven recently that the lepidopteran immune system can react in different ways because the different classes of microorganisms each induce the synthesis of a particular subset of antimicrobial peptides (Mak et al., 2010). In Lepidoptera, members of linear $\alpha$-helical (cecropins and moricins), cysteine-stabilized (defensins), proline-rich and glycine-rich inducible antimicrobial peptides have been identified (Brown et al., 2009); moreover the peptides cooperate with lysozyme, which occurs naturally in haemolymph.

The aim of this study was to develop a new method of analyzing the antibacterial activity of insect haemolymph based on a direct real-time measurement of changes in bioluminescence produced by P. luminescens or E. coli K12.

\section{MATERIAL AND METHODS}

\section{P. luminescens batch culture preparation}

Photorhabdus luminescens, subsp. kayaii was inoculated on nutrient agar plates after isolation from surface sterilized cadavers of Galleria mellonella infected with the entomopathogenic nematode Heterorhabditis bacteriophora in Petri dishes lined with filter paper. After overnight incubation colonies of $P$. luminescens were transferred to LB medium and gently shaken (GFL 3005 , Germany) for one hour. The bacterial suspension was then adjusted to an optical density 0.1 at $400 \mathrm{~nm}$ using a JENWAY 7300 spectrophotemeter (UK). Bacterial cells were separated by centrifugation (2000 RPM for $10 \mathrm{~min}$ ) using a JANETZKI K23 centrifuge (Germany), twice washed and finally re-suspended in phosphate buffer (PB, $\mathrm{pH} 7)$. The bacterial suspensions were stored at $4^{\circ} \mathrm{C}$ and used for up to seven days.

\section{E. coli batch culture preparation}

Bacteria E. coli $\mathrm{K} 12$ with luxABCDEamp genes and resistant to ampicillin were cultivated overnight at $37^{\circ} \mathrm{C}$ in $\mathrm{LB}$ medium and constantly shaken (Memmert WNB 22, Germany). This suspension was diluted to an optical density 0.1 at $620 \mathrm{~nm}$ and incubated until the optical density reached 0.45 . The bacterial suspension was then adjusted to an optical density 0.1 at $620 \mathrm{~nm}$ and centrifuged (2000 RPM for $10 \mathrm{~min}$ ) using a JANETZKI K23 centrifuge (Germany). Bacterial cells were washed twice in LB and concentrated by re-suspending in 80 times less volume of LB medium. Suspension was then mixed $1: 1$ with $50 \%$ glycerol and stored at $-80^{\circ} \mathrm{C}$. All E. coli media contained $100 \mu \mathrm{g} / \mathrm{ml}$ of ampicillin in order to sustain the selection.

\section{Bacterial working cultures}

Both P. luminescens and E. coli batch suspensions were inoculated on nutrient agar plates in 6 different dilutions $\left(10^{3}-10^{8}\right.$ times) for bacterial cells quantity estimation. After overnight cultivation the numbers of colonies (CFU) were counted on all the agar plates. Bacterial working cultures were adjusted by adding a certain volume of $\mathrm{PB}(\mathrm{pH} 7)$ to give a concentration of 250000 bacterial cells per $100 \mu$ l of suspension.

\section{Luminometry}

Bioluminescence of bacterial suspensions mixed with insect haemolymph was measured using microtitre plates on three separate experiments. In each experiment luminescence was measured at $30^{\circ} \mathrm{C}$ over a period of one hour using plate luminometer Chameleon $\mathrm{V}^{\mathrm{TM}}$ (Hidex, Finland). The light emitted during the reaction is positively correlated with bacterial viability (Atosuo et al., 2013). Luminescence signal was measured in counts per second (CPS).

\section{Bacterial viability measurements}

CFU were counted in both $E$. coli and P. luminescens suspensions at 0,30 and 60 min after being mixed with haemolymph. Both untreated suspensions of bacteria and those mixed with haemolymph were diluted logarithmically and plated on dishes containing nutrient agar. Number of colonies was determined after overnight incubation at $37^{\circ} \mathrm{C}$ for $E$. coli and $30^{\circ} \mathrm{C} \mathrm{P}$. luminescens.

\section{Haemolymph collection}

Bombyx mori L. (Lepidoptera: Bombycidae, Greek mono-voltine white hybrid) larvae ( $\mathrm{V}^{\text {th }}$ instar, 5 days old) were reared on mulberry leaves in a laboratory. G. mellonella L. (Lepidoptera: Pyralidae) larvae (VII ${ }^{\text {th }}$ instar, 3-4 days old) were obtained from laboratory cultures maintained on an artificial diet (Haydak, 1936) at $29 \pm 1{ }^{\circ} \mathrm{C}$ in constant darkness. Haemolymph with haemocytes was collected by proleg amputation and pooled in Eppendorf tubes containing several crystals of phenylthiourea (PTU) as an anticoagulant. A mixture of haemolymph from five larvae diluted in $\mathrm{PB}(\mathrm{pH} 7)$ was added directly to $120 \mu 1$ of bacterial suspension in microtitre plates to a total volume of $200 \mu \mathrm{l} /$ well.

\section{Fractionation and inactivation of haemolymph}

Haemocyte-free Bombyx mori haemolymph was prepared by centrifugation at 6000 RPM for 10 min using a Microspin 12 (BioSan, Latvia). Heat inactivated haemocyte-free haemolymph was prepared by raising the temperature of freshly pooled haemolymph up to $90^{\circ} \mathrm{C}$ for 5 min using a block heater SBH130D (Stuart, UK). Plasma was obtained by centrifugation of inactivated haemolymph at 6000 RPM for 10 min using a Microspin 12.

\section{Induction of antimicrobial peptides}

Proleg of a $B$. mori larva was pricked with a needle previously dipped in sterile insect saline or bacterial suspension (E. coli or $P$. luminescens). Untreated larvae were used as a control. After five hours of incubation haemolymph was collected for measuring antibacterial activity as described above.

\section{RESULTS}

\section{Dose dependence of antimicrobial activity}

The antibacterial activity of insect haemolymph against Gram negative bacteria recorded in the bioluminescence assay was very high. The dose dependence of the antibacterial activity was revealed by using different concentrations of B. mori haemolymph (Fig. 1). We observed a significant decrease in the bioluminescence signal using samples mixed with $B$. mori haemolymph over a period of one hour. Concentrations of haemolymph ranging from $0.5 \%$ to $6 \%$ were tested against both E. coli (Fig. 1a) and P. luminescens (Fig. 1b). In subsequent experiments, the optimal dilution used was $1 \%$ haemolymph, a volume that it is possible to obtain from small insect larvae, such as those of G. mellonella, which can suppress approximately $40-70 \%$ of the bacteria in $30 \mathrm{~min}$ (Fig. 2). 

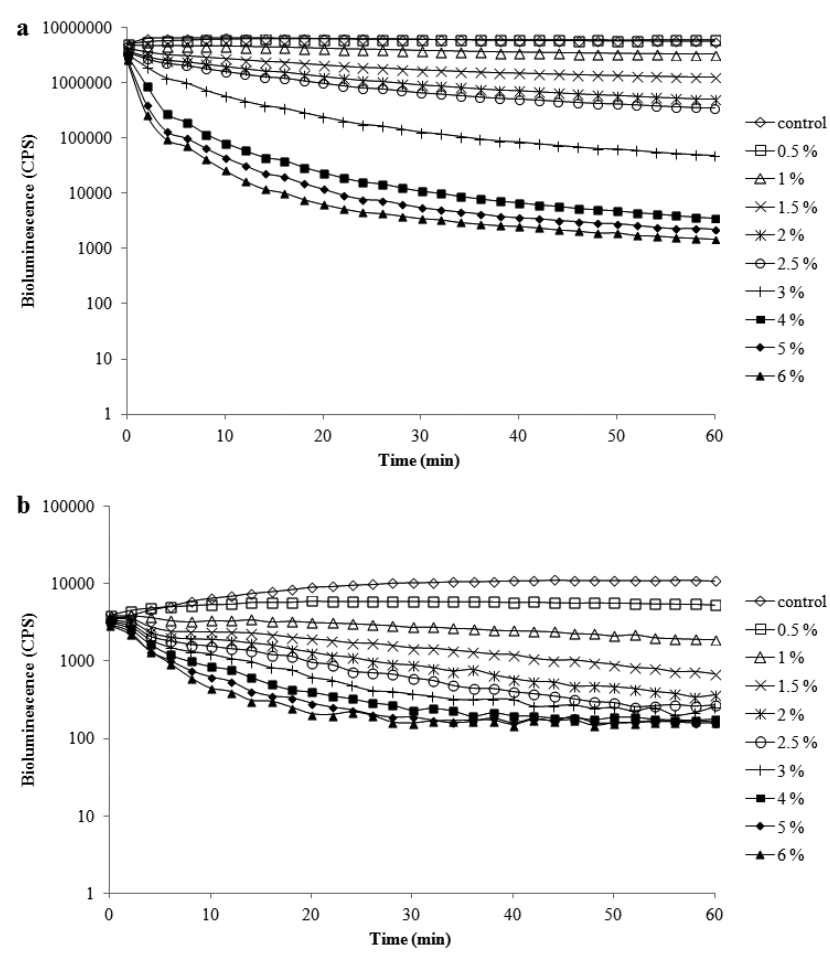

Fig. 1. Dependence of the bioluminence/antibacterial activity on the concentration of $B$. mori haemolymph recorded against bioluminescent $E$. coli (a) and P. luminescens (b) at $30^{\circ} \mathrm{C}$. Bioluminescence of untreated bacteria (control; $3 \times 10^{5}$ bacterial cells per well) and after exposure to $B$. mori haemolymph $(0.5-6 \%)$ is expressed on logarithmic scale in counts per second (CPS).

\section{Bioluminescent signal corresponds to bacterial viability}

To confirm that the bioluminescence signal corresponds to bacterial viability, $1 \%$ haemolymph was used in both the luminometric and CFU counting experiments. Bacterial suspension from bioluminescent assay was inoculated on to agar plates 0,30 or 60 min after mixing with $1 \%$ haemolymph. Compared to the untreated bacterial suspensions that produce maximal bioluminescence and maximum CFU both $E$. coli and P. luminescens suspensions mixed with haemolymph produced less bioluminescence and CFU. For both E. coli and P. luminescens the three independent measurements were performed with no statistical difference between plating and luminometry (Fig. 3).

\section{Is the antimicrobial activity measured of humoral origin?}

To determine the source of antibacterial activity we compared the antimicrobial effect of fresh haemolymph with that of haemocyte-free haemolymph, haemolymph stored at $-80^{\circ} \mathrm{C}$ for $2 \mathrm{~h}$ and heat inactivated haemolymph plasma; all at a final concentration $1 \%$. The antibacterial activity of fresh haemolymph was similar to that of haemocyte-free and freeze-melted haemolymph. Bioluminescence signal differed insignificantly $(<5 \%)$ in measurements using E. coli (Fig. 4a) and $(<3 \%$ ) P. luminescens (Fig. 4b) in all three haemolymph samples, which indicates that the antibacterial activity measured was due to humoral factors active against these Gram negative bacteria. This
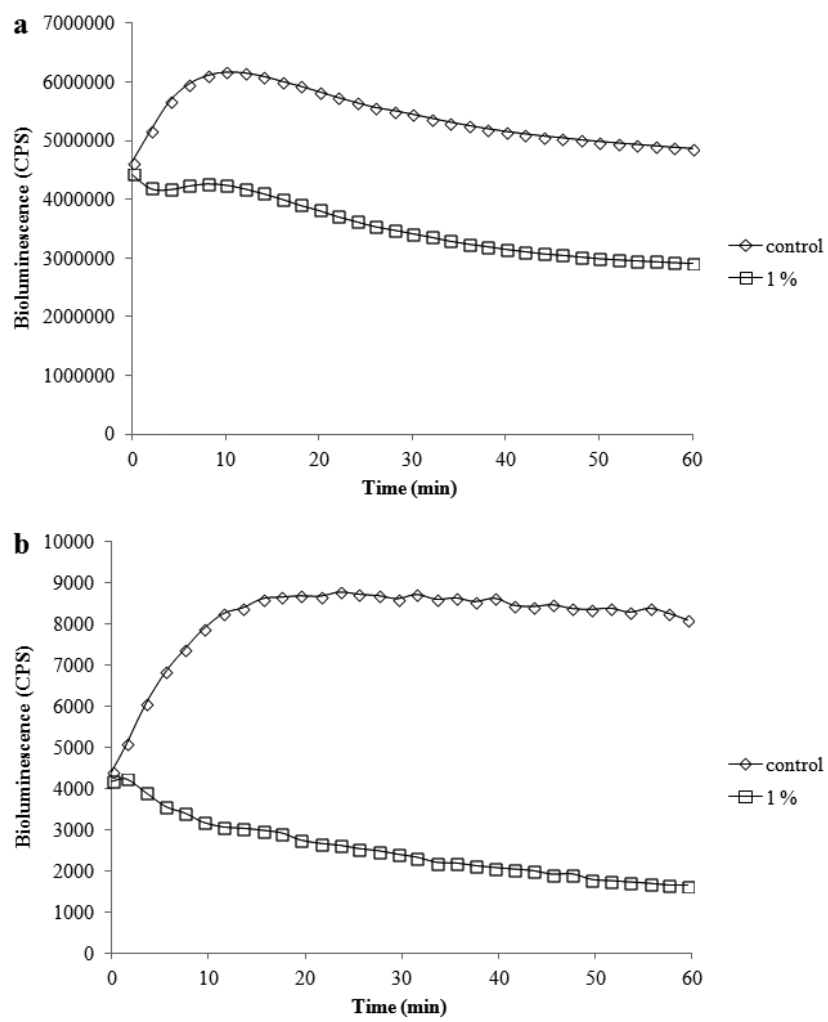

Fig. 2. Antibacterial activity of $1 \% B$. mori haemolymph recorded against E. coli (a) and P. luminescens (b) at $30^{\circ} \mathrm{C}$ expressed as a decline in bioluminescence expressed in counts per second (CPS). Each well contained $3 \times 10^{5}$ bacterial cells.

was confirmed by mixing bacterial suspensions with heat inactivated haemolymph plasma, which resulted in no antimicrobial activity (due to lack of any functional antimicrobial proteins). Moreover, inactivated haemolymph plasma can serve as a source of nutrition for the bacteria, which resulted in the bioluminescence signal of bacterial suspensions mixed with inactivated haemolymph plasma being even greater than that produced by the untreated control suspension. Recorded bioluminescence was approximately $40 \%$ higher for the E. coli (Fig. 4a) and $15 \%$ for the $P$. luminescens (Fig. 4b) suspensions mixed with $1 \%$ inactivated cell-free haemolymph plasma.

\section{Measured antibacterial activity is mediated by inducible factors}

To ensure that our assay is suitable for evaluating antibacterial activity in all insects we carried out similar experiments to those cited above using haemolymph of $G$. mellonella, a widely used Lepidopteran model organism. As recorded for B. mori, $1 \%$ haemolymph from $G$. mellonella had a strong antibacterial activity against both $E$. coli and $P$. luminescens, resulted in an approximately $40-70 \%$ decrease in the bacterial bioluminescence signal within $30 \mathrm{~min}$.

\section{Measured antibacterial activity is mediated by inducible factors}

Use of haemolymph from untreated insects indicated that our method of assessing antibacterial activity works and helped to elucidate the mechanisms that might operate 

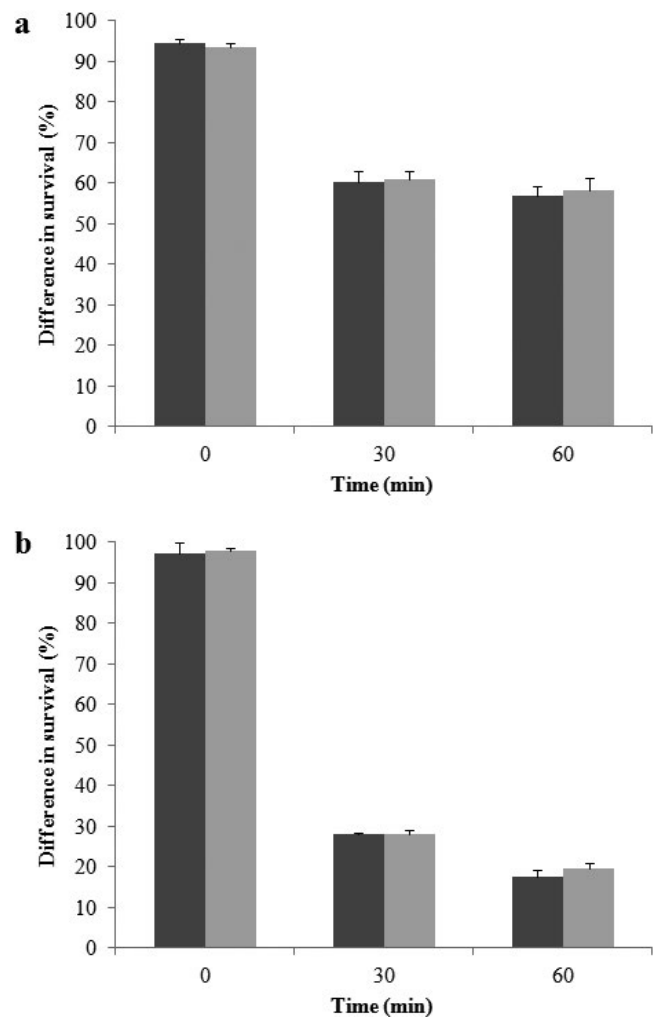

Fig. 3. Decrease in bacterial viability recorded in bacterial suspensions mixed with $1 \%$ haemolymph compared to untreated bacterial suspension $\left(30^{\circ} \mathrm{C}, 3 \times 10^{5}\right.$ bacterial cells per well). Changes in viability of $E$. coli (a) or P. luminescens (b) were measured using the bioluminescent assay and CFU counting. Results are expressed as differences in survival of untreated and haemolymph-treated bacterial suspensions in percentages \pm SD.

against Gram negative bacteria. To highlight the practical use of the assay, untreated larvae were compared to larvae pricked with a bacterial suspension to induce antibacterial activity prior to the bioluminescent assay. B. mori larvae infected with $E$. coli or $P$. luminescens showed a higher antibacterial activity five hours after infection. The increase in antibacterial activity was reflected in decreased $E$. coli bioluminescence, which was significantly different from that of the untreated control and larvae injected with insect saline ( $46 \%$ decline in bioluminescence in $30 \mathrm{~min}$ ). Insects treated with bacterial suspensions had a stronger antibacterial response, $31 \%$ and $18 \%$, respectively, for $E$. coli and $P$. luminescens, after $30 \mathrm{~min}$, than larvae treated with insect saline (Fig. 5).

\section{DISCUSSION AND CONCLUSIONS}

In this study we show that bioluminescent bacteria can be used for determining antibacterial activity of samples of insect haemolymph. P. luminescens, which is a natural insect pathogen with a low temperature optimum, would be an ideal bioluminescent bacterium for analyzing samples of haemolymph from invertebrates but for the fact it is difficult to isolate and store, whereas bioluminescent $E$. coli seems to be a more suitable system for carrying out antibacterial assays. E. coli emits a greater bioluminescence signal than $P$. luminescens, because the original lux genes
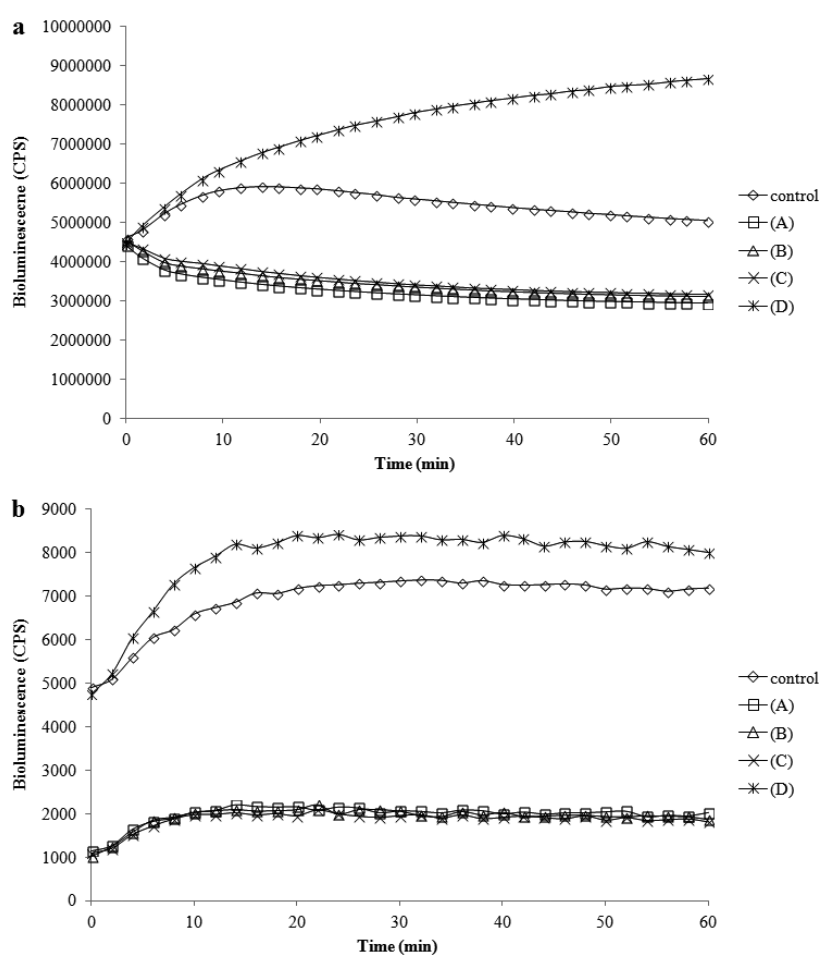

Fig. 4. Antibacterial activity against E. coli (a) and P. luminescens (b) recorded in $1 \%$ fresh (A), haemocyte-free (B), freezemelted (C) and heat inactivated (D) haemolymph of B. mori expressed as the decline in bioluminescence in counts per second (CPS). Experiment was performed at $30^{\circ} \mathrm{C}$ with $3 \times 10^{5}$ bacterial cells per well.

are located on a chromosome in P. luminescens whereas in E. coli they are present in multicopy plasmids (Atosuo et al., 2013).

The bioluminescence measurements are expressed in terms of CPS, which are dependent on bacterial growth and viability. Even when the same methods of preparation are used bioluminescence can differ among individual stocks of bacteria, thus the absolute values of CPS could have differed slightly between replicates in our experiments, but the trend in bacterial growth assumed based on the biolu-

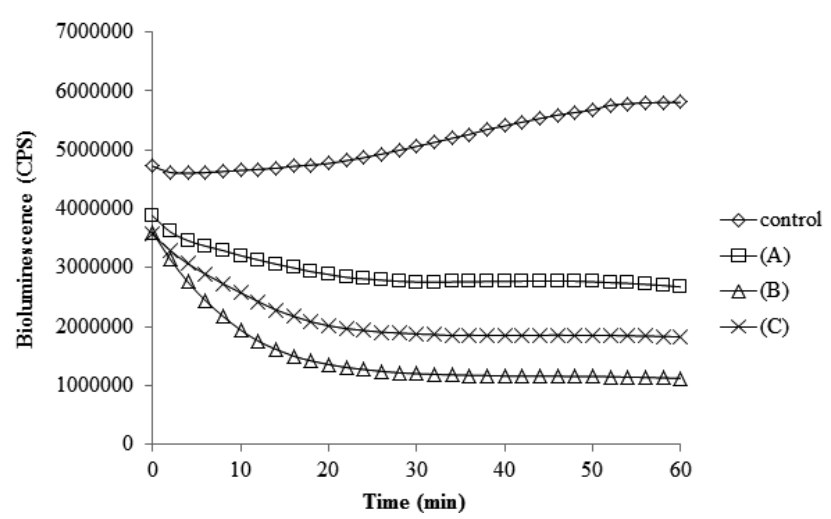

Fig. 5. Influence of septic injury on antibacterial activity against E. coli of $1 \%$ B. mori haemolymph at $30^{\circ} \mathrm{C}$. B. mori larvae were either pricked with a sterile needle (saline, A), needle dipped in a suspension of E. coli (B) or P. luminescens (C). Decline in bioluminescence is expressed in counts per second (CPS). Each well contained $3 \times 10^{5}$ bacterial cells. 
minescence can still be compared, even that recorded in different sets of experiments.

The decrease in bacterial viability recorded using our assay was very rapid and occurred within 20 min after mixing the bacteria with the haemolymph. Fast responses similar to this are most likely to be mediated by constitutively present immune factors rather than inducible effectors, which are thought to be the primary protection against bacteria within the body of an insect (Haine et al., 2008). It is thought that most of the bacteria entering the body of an insect are captured near the wound site and prior to that we have shown that bacteria can be quickly destroyed, e.g., by entrapment of the bacteria in a clot (Wang et al., 2010). In our assay we used haemolymph samples treated with PTU, which acts as anticoagulant and inhibits the activation of the phenoloxidase system, but we did not record any changes in bacterial survival when coagulation was inhibited.

Futhermore, the minor role of haemocytes in the antibacterial response measured by our method was confirmed by comparing the result for whole heamolymph with that of haemocyte-free samples from which immune cells were eliminated by centrifugation, freeze-melting or even by overall inactivation. When centrifuged or freeze-melted haemolymph was used the same decrease in bacterial viability was recorded as when whole haemolymph and inactivated haemolypmh plasma were used as indicated by the increase in the bioluminescence signal. We suppose that haemocyte-free and inactivated haemolymh plasma provided nutrition for bacterial growth. All these facts demonstrate that the antibacterial activity measured is of humoral origin. Insects do not have a complement system acting against Gram negative bacteria as in vertebrates and thus it is most likely that AMPs are responsible for the bactericidal effect. Most of the AMPs detectable in haemolymph upon microbial infection are produced within a few hours by the fat body, but haemocytes and other specific tissues also produce AMPs and secrete them into the haemolymph (Lemaitre \& Hoffmann, 2007). Apart from the induced synthesis of AMPs there is also a constitutive level of AMPs present in haemolymph. Using the bioluminescence assay we were able to measure the total antibacterial activity of haemolymph against Gram negative bacteria, which is likely to involve synergistic activities of several different AMPs belonging to several peptide groups.

In $B$. mori five families of AMPs are described, mostly consisting of several forms of related peptides; namely linear $\alpha$-helical cecropins and moricins (Kaneko et al., 2007; Hara \& Yamakawa, 1995b), cysteine-rich peptides (Kaneko et al., 2008), proline-rich lebocins (Hara \& Yamakawa, 1995a) and glycine-rich attacins and gloverins (Sugiyama et al., 1995; Kaneko et al., 2007). G. mellonella is also known to produce several different AMPs, including linear $\alpha$-helical cecropins and moricin-like peptides (Kim et al., 2004; Brown et al., 2009), cysteine-rich defensins such as galiomicin and gallerimycin (Schuhmann et al., 2003; Lee et al., 2004), proline-rich peptides (Mak et al., 2001), anionic peptide 1 and 2 (Cytrynska et al., 2007) and the glycine-rich peptide gloverin (Seitz et al., 2003). Futhermore, some proteins, including apolipophorin III, gallysin and inducible inhibitors of metalloproteinases are considered to have a role in antimicrobial protection (Wojda et al., 2009). Members of the cecropin, moricin, attacin and lebocin peptide family are active against Gram negative bacteria and also have synergic functional relationship with other AMPs specific for Gram positive bacteria and even the fungi infecting both B. mori and G. mellonella.

It is known that bacterial cells became more susceptible to AMPs in the presence of lysozyme and there is a synergistic action with cecropin $\mathrm{B}$, attacin and defensin against E. coli (Engstrom et al., 1984; Chalk et al., 1994). We did not record any changes in antibacterial activity after treatment of haemolymph with the SDS, which inhibits lysozyme activity. Moreover, recombinant E. coli was not killed by pure lysozyme (unpubl. data) indicating that it has an insignificant role in the antibacterial activity recorded by our assay.

Eleftherianos et al. (2006) show that previous infection with non-pathogenic bacteria $(E$. coli) causes a subsequent enhancement of the immunity to infection of insects by $P$. luminescens. Our results confirmed that the bactericidal effect of insect haemolymph exposed to both $E$. coli and $P$. luminescens is significantly greater than the antibacterial activity of the haemolymph of larvae after aseptic injury.

In summary, we feel that the bioluminescence assay proposed can be used as a innovative, fast, cheap and realtime method for assessing haemolymph antibacterial activity similar to the determination of complement activity in vertebrates, such as that in fish serum (Buchtikova et al., 2011). Other methods used for this, such as counting CFUs, optical density measurements, zone diffusion assays, protein electrophoresis, HPLC and others are more time consuming, more difficult to prepare and need large samples for determining the level of antibacterial activity.

ACKNOWLEDGEMENTS. Our research was supported by research grants from the Grant Agency of the Czech Republic (GA206/09/P470), NAZV-KUS 2012 (QJ1210047), European Social Fund and state budget of Czech Republic (CZ.1.07/2.3.00/30.0009) and a Masaryk University grant (MUNI/A/0927/2013). We are grateful to E.-M. Lilius (University of Turku, Finland), U. Theopold (Stockholm University, Sweden) and N. Krishnan (Mississippi State University, USA) for their useful comments on draft of this article.

\section{REFERENCES}

Atosuo J., Lehtinen J., Vojtek L. \& Lilius E.M. 2013: Escherichia coli K-12 (pEGFPluxABCDEamp): a tool for analysis of bacterial killing by antibacterial agents and human complement activities on a real-time basis. - Luminescence 28: 771-779.

Boemare N.E., Akhurst R.J. \& Mourant R.G. 1993: DNA relatedness between Xenorhabdus spp. (Enterobacteriaceae), symbiotic bacteria of entomopathogenic nematodes, and a proposal to transfer Xenorhabdus luminescens to a new genus, Photorhabdus gen. nov. - Int. J. Syst. Bacteriol. 43: 249-255.

Brown S.E., Howard A., KasprzaK A.B., Gordon K.H. \& East P.D. 2009: A peptidomics study reveals the impressive antimicrobial peptide arsenal of the wax moth Galleria mellonella. — Insect Biochem. Mol. Biol. 39: 792-800. 
Buchtikova S., Simkova A., Rohlenova K., Flajshans M., LoJEK A., Lilius E.M. \& HYrsL P. 2011: The seasonal changes in innate immunity of the common carp (Cyprinus carpio). Aquaculture 318: 169-175.

Chalk R., Townson H., Natori S., Desmond H. \& Ham P.J. 1994: Purification of an insect defensin from the mosquito, Aedes aegypti. - Insect Biochem. Mol. Biol. 24: 403-410.

Cytrynska M., Mak P., Zdybicka-Barabas A., Suder P. \& JAKUBOwICZ T. 2007: Purification and characterization of eight peptides from Galleria mellonella immune hemolymph. Peptides 28: 533-546.

Eleftherianos I., Marokhazi J., Millichap P.J., Hodgkinson A.J., Sriboonlert A., fFrench-Constant R. \& Reynolds S.E. 2006: Prior infection of Manduca sexta with non-pathogenic Escherichia coli elicits immunity to pathogenic Photorhabdus luminescens: Roles of immune-related proteins shown by RNA interference. - Insect Biochem. Mol. Biol. 36: 517-525.

Engstrom P., Carlsson A., Engstrom A., Tao Z.J. \& Bennich H. 1984: The antibacterial effect of attacins from the silk moth Hyalophora cecropia is directed against the outer membrane of Escherichia coli. — Embo J. 3: 3347-3351.

ffrench-Constant R., Waterfield N., Daborn P., Joyce S., Bennet H., Au C., Dowling A., Boundy S., Reynolds S. \& Clarke D. 2003: Photorhabdus: towards a functional genomic analysis of a symbiont and pathogen. - FEMS Microbiol. Rev. 26: $433-456$.

Haine E.R., Moret Y., Siva-Jothy M.T. \& RolfF J. 2008: Antimicrobial defense and persistent infection in insects. - Science 322: $1257-1259$.

Hara S. \& Yamakawa M. 1995a: A novel antibacterial peptide family isolated from the silkworm, Bombyx mori. - Biochem. J. 310: 651-656.

Hara S. \& Yamakawa M. 1995b: Moricin, a novel type of antibacterial peptide isolated from the silkworm, Bombyx mori. J. Biol. Chem. 270: 29923-29927.

HAYDAK M.H. 1936: A food for rearing laboratory insect. J. Econ. Entomol. 29: 1026.

Kaneko Y., Furukawa S., Tanaka H. \& Yamakawa M. 2007: Expression of antimicrobial peptide genes encoding Enbocin and Gloverin isoforms in the silkworm, Bombyx mori. - Biosci. Biotechnol. Biochem. 71: 2233-2241.

Kaneko Y., Tanaka H., Ishibashi J., Iwasaki T. \& Yamakawa M. 2008: Gene expression of a novel defensin antimicrobial peptide in the silkworm, Bombyx mori. - Biosci. Biotechnol. Biochem. 72: 2353-2361.

Kilpi M., Atosuo J. \& Lilius E.M. 2009: Bacteriolytic activity of the alternative pathway of complement differs kinetically from the classical pathway. - Dev. Comp. Immunol. 33: 1102-1110.

Kim C.H., Lee J.H., Kim I., Seo S.J., Son S.M., Lee K.Y. \& Lee I.H. 2004: Purification and cDNA cloning of a cecropin-like peptide from the great wax moth, Galleria mellonella. - Mol. Cells 17: 262-266.
Lee Y.S., Yun E.K., Jang W.S., Kim I., Lee J.H., Park S.Y., Ryu K.S., Seo S.J., Kim C.H. \& Lee I.H. 2004: Purification, cDNA cloning and expression of an insect defensin from the great wax moth, Galleria mellonella. _ Insect Mol. Biol. 13: 65-72.

Lemaitre B. \& Hoffmann J. 2007: The host defense of Drosophila melanogaster. - Annu. Rev. Immunol. 25: 697-743.

Mak P., Chmiel D. \& GaceK G.J. 2001: Antibacterial peptides of the moth Galleria mellonella. — Acta Biochim. Pol. 48: 1191-1195.

Mak P., Zdybicka-Barabas A. \& Cytrynska M. 2010: A different repertoire of Galleria mellonella antimicrobial peptides in larvae challenged with bacteria and fungi. - Dev. Comp. Immunol. 34: 1129-1136.

Nikoskelainen S., Lehtinen J. \& Lilius E.M. 2002: Bacteriolytic activity of rainbow trout (Oncorhynchus mykiss) complement. — Dev. Comp. Immunol. 26: 797-804.

Poinar G.O., Thomas G., Haygood M. \& Nealson K.H. 1980: Growth and luminescence of the symbiotic bacteria associated with the terrestrial nematode Heterorhabditis bacteriophora. - Soil Biol. Biochem. 12: 5-10.

Schuhmann B., Seitz V., Vilcinskas A. \& Podsiadlowski L. 2003 : Cloning and expression of gallerimycin, an antifungal peptide expressed in immune response of greater wax moth larvae, Galleria mellonella. - Arch. Insect Biochem. Physiol. 53: 125-133.

Seitz V., Clermont A., Wedde M., Hummel M., Vilcinskas A., Schlatterer K. \& Podsiadlowski L. 2003: Identification of immunorelevant genes from greater wax moth (Galleria mellonella) by a subtractive hybridization approach. - Dev. Comp. Immunol. 27: 207-215.

Sugiyama M., Kuniyoshi H., Kotani E., Taniai K., Kadono-OKuda K., Kato Y., Yamamoto M., Shimabukuro M., Chowdhury S., Xu J., Choi S.K., Kataoka H., SuzuKi A. \& Yamakawa M. 1995: Characterization of a Bombyx mori cDNA encoding a novel member of the attacin family of insect antibacterial proteins. - Insect Biochem. Mol. 25: 385-392.

VirTa M., Karp M., Ronnemaa S. \& LiLius E.M. 1997: Kinetic measurement of the membranolytic activity of serum complement using bioluminescent bacteria. - J. Immunol. Meth. 201: 215-221.

Wang Z., Wilhelmsson C., Hyrsl P., Loof T.G., Dobes P., Klupp M., Loseva O., Morgelin M., Iklé J., Cripps R.M., Herwald H. \& Theopold U. 2010: Pathogen entrapment by transglutaminase - a conserved early innate immune mechanism. - PLoS Pathog. 6: e1000763.

WoJdA I., KowALSKI P. \& JAKUBOWICZ T. 2009: Humoral immune response of Galleria mellonella larvae after infection by Beauveria bassiana under optimal and heat-shock conditions. $-J$. Insect. Physiol. 55: 525-531.

Received February 5, 2014; revised and accepted March 31, 2014 Prepublished online May 6, 2014 